\title{
Self-authenticity, Optimism, and Neuroticism in relation to Basic Psychological
}

\section{Needs}

\author{
Daniela Ionescu ${ }^{1} * \&$ Claudia Iacob ${ }^{2}$ \\ ${ }^{I}$ Departament of Psychology, National School of Political and Administrative Studies, Bucharest, Romania \\ ${ }^{2}$ Departament of Psychology, University of Bucharest, Romania
}

Received 7.05.2019; Received revised 15.06.2019; Accepted 28.06.2019

Available online 30.06.2019

\begin{abstract}
This paper aimed at investigating the mediating role of one personality construct (i.e., dispositional optimism) on the relationship between self-authenticity and basic psychological needs (BPN) satisfaction. This study also aims to investigate the predictive role of three personality constructs (self-authenticity, optimism, and neuroticism) on basic psychological needs satisfaction. The participants were 566 Romanian adults from the general population $(M=43.66$ years old, $S D=$ 10.46), who were asked to fill in multiple questionnaires. Findings reveal that optimism mediates the relationship between self-authenticity and the satisfaction of the need for autonomy $(\beta=.30$, $\left.R^{2}=.39, p<0.001\right)$ and also mediates the relationship between self-authenticity and the satisfaction of the need for competence $\left(\beta=.51, R^{2}=.36, p<0.001\right)$, but does not mediate the relationship between self-authenticity and the need for relatedness. Another result of this study is that the three personality factors (self-authenticity, optimism, and neuroticism) predict altogether the satisfaction of basic psychological needs $\left(\beta=-.11, R^{2}=.52, p<0.05\right)$. These results extend the current knowledge about personality determinants involved in autonomy, competence and relatedness basic needs from self-determination theory. In the end, the authors discuss the implications of the findings, the limits of the present study and future research suggestions.
\end{abstract}

Keywords: basic psychological needs satisfaction, self-authenticity, optimism, neuroticism

Address of correspondence: Claudia I. Iacob, Departament of Psychology, University of Bucharest, Panduri Street, No. 90, Sector 5, Bucharest, Romania.

E-mail: claudia.iuliana.draganescu@drd.unibuc.ro

\section{Introduction}

Self-determination theory (SDT) postulates that there are three basic psychological needs (i.e. autonomy, competence, and relatedness) that must be satisfied in order to obtain performance and well-being. The need for autonomy is reflected by self-generated and pursued actions that lead to goal accomplishment. The need for competence is evident in the person's orientation towards success in activities. Finally, the relatedness need is the expression of wanting to have good interpersonal relationships and genuine connections with others (Deci \& Ryan, 2000).

Low satisfaction of these needs is a predictor for low well-being, but not for poor mental health (Quested \& Duda, 2010). However, need frustration is a predictor for ill-being (Cordeiro, Paixão, Lens, Lacante, \& Luyckx, 2016), even when controlled for the effects of Big-Five personality traits (Nishimura \& Suzuki, 2016). Its explicative utility has been demonstrated in young people's decisions of disclosing their HIV status (Gillard \& Roark, 2013). In recent times, SDT is being used also as a resilience framework for managing chronic pain in the pediatric population (Riggenbach, Goubert, Van Petegem, $\&$ Amouroux, 2019). All these demonstrate the usefulness of SDT for explaining optimization and personal development in human behaviour. Hence, the importance of taking a closer look at psychological variables that impact basic psychological need satisfaction (i.e., BPN satisfaction).

According to SDT, people are authentic when their actions reflect their true self, they are self-determined and autonomous (Deci \& Ryan, 2000). Other authors, offer similar definitions, stating that authenticity is the "sense or feeling that one is currently in alignment with one's true or genuine self" (Sedikides, Slabu, Lenton, \& Thomaes, 
2017, p. 521). This feeling of self-authenticity is a result of the interaction between mental, behavioural and emotional processes. When they fail, these people try to find real solutions for their problems and they are less concerned with the way other people perceive them. On the contrary, when they succeed, they don't exaggerate the personal contribution to the success and they don't "show off" (Knee \& Zuckerman, 1998). Self-authenticity is mostly tied to autonomy need and is one of the variables that lead to BPN satisfaction.

Other variables studied in relation to SDT are personality traits, divided into obstacles and facilitators of basic psychological needs satisfaction. In this paper, we will refer to dispositional optimism as a facilitator and neuroticism as an obstacle.

Dispositional optimism is a personality trait characterized by positive expectations in different life domains and circumstances (Scheier \& Carver, 1985). This tendency is relatively stable. In this model, optimism is a unidimensional construct, as opposed to pessimism, which is characterized by negative expectations for the future (Scheier \& Carver, 1985). Other models postulate a two-dimensional structure, where optimism and pessimism are related (Chang, D'Zurilla, \& Maydeu-Olivares, 1994). Another view comes from positive psychology, where optimism constitutes an attributional style, defined by the tendency to believe that negative events are external, inconstant and specific (Peterson \& Seligman, 1987). Therefore, an optimistic person believes that she is not responsible for the negative situation, which probably won't repeat itself, and that this unfortunate event will not impact all life domains, but rather a small, specific, part of it. In this article, the authors used the unidimensional approach.

Over time, studies revealed that optimism is an important predictor for many outcomes, including mental and physical well-being, life satisfaction (Halama \& Dedova, 2007; Wrosch \& Scheier, 2003) and also, mental health (Kovess-Masféty, 2003). It is assumed that all these benefits come from the adaptive behavioural and cognitive consequences of optimism (e.g., healthy lifestyle, greater mental flexibility, good problem-solving skills, adaptive appraisals of negative events) (Conversano et al., 2010). A scientific explanation for these results can be derived from SDT. Self-concordant and self-authentic goals will direct the behaviour towards accomplishing those goals. Optimism and the belief in success facilitate the allocation of resources for goal accomplishment and self-concordant goals validate this belief. On the contrary, extrinsic goals or goals that are not in concordance with the self, consume resources and they are less likely to be successfully accomplished. Previous investigations bring evidence that optimism is a positive predictor of all three basic psychological needs (Desrumaux et al., 2015) and neuroticism is a negative predictor of the same criterion (Ionescu, 2017).

Neuroticism is a major construct in personality and, at a behavioural level, it entails the tendency towards experiencing negative emotions. From a neurological perspective, it implies fast arousal in the presence of stimuli and slow inhibition processes (Costa \& McCrae, 1992). In a broad sense, people who score high on this trait use maladaptive coping mechanisms, are more likely to appraise situations as stressful, they frequently experience adverse emotions and they are more vulnerable to psychopathology (Ormel, Rosmalen, \& Farmer, 2004).
These results pinpoint to the fact that neuroticism has a negative impact on many life domains.

Regarding SDT, neuroticism (i.e., negative affectivity) sabotages the process of goal pursuit and BPN satisfaction. Negative affectivity is associated with low skills of goal pursuit because those people don't have effective selfregulation strategies. So, self-control resources are usually directed towards managing negative emotions (Baumeister, Vohs, \& Tice, 2007). This is consistent with other research that shows the tendency of individuals with high neuroticism for affect control goals (Reisz, Boudreaux, \& Ozer, 2013). In relation to other goals, these people have anticipatory anxiety and find goal pursuit as being ineffective. So, they tend to avoid it in order to escape the feeling of distress (Elliot, Sheldon, \& Church, 1997). Also, neuroticism a correlates with low levels of satisfaction for all three basic psychological needs (Judge, Bono, Erez, \& Locke, 2005).

On the other hand, emotionally balanced and selfauthentic people, tend to be pleased with themselves, they experience more positive emotions and psychological wellbeing (Saricaoğlu \& Arslan, 2013).

Neuroticism is a moderator of the relationship between self-authenticity (i.e., predictor) and depressive symptoms (i.e., criterion). At high levels of neuroticism, the negative association between these two variables is diminished. In other words, people with negative affectivity that are not in contact with themselves are more likely to experience depressive symptoms through the presence of dysfunctional negative cognitions, such as ruminations and worries (Wasylkiw, Fabrigar, Rainboth, Reid, \& Steen, 2010).

\section{Research hypotheses}

In conclusion, previous work has shown the importance of BPN satisfaction for human goal accomplishment, optimization and well-being. Dispositional optimism and neuroticism are among the studied predictors of BPN satisfaction that facilitate and, respectively hinder the positive consequences of BPN. This paper probes deeper into the role of optimism and neuroticism and aimed at testing the mediating role of optimism on the relationship between self-authenticity and the three basic psychological needs. The authors formulated the following hypotheses:

H1. Dispositional optimism mediates the relationship between self-authenticity and the satisfaction of the need for autonomy. Otherwise said, self-authentic people tend to be more optimistic and thus will report a bigger satisfaction of their need for autonomy.

H2: Optimism mediates the relationship between selfauthenticiy and the satisfaction of the need for competence. Otherwise said, self-authentic people tend to be more optimistic and thus will report a bigger satisfaction of their need for competence.

H3: Optimism mediates the relationship between selfauthenticity and the satisfaction of the need for relatedness. Otherwise said, self-authentic people tend to be more optimistic and thus will report a bigger satisfaction of their need for relatedness.

H4. Self-authenticity, optimism and neuroticism predict alltogether one`s basic psychological needs satisfaction. Otherwise said individulas who are authetinc with themselves, optimistic and who have low levels of neuroticism will report a bigger satisfaction of their basic psychological needs. 


\section{Method}

Participants and Procedure

The research sample consists of 566 participants from the general Romanian population. Their age varies between 18 and 78, with mean age $M=43.66, S D=10.46$. The gender distribution is relatively balanced, with 308 females $(M=33.14, S D=13.11)$ and 258 males $(M=40.25, S D=$ 12.91). The participants volunteered to fill in the questionnaires, so this is a convenience sample. There were no specific inclusion criteria in the study and the participants did not receive any rewards. This study has a cross-sectional design.

The questionnaires were printed and completed by undergraduate psychology students from the University of Bucharest. Each student recommended 2 adults over 30 years old that also participated in this study. Upon completion, the scales were handed over to the researchers.

\section{Instruments}

Basic psychological need satisfaction. To assess this construct we used the Basic Need Satisfaction in General instrument (Deci \& Ryan, 2000), which measures autonomy needs satisfaction, competence and relatedness. In other words, it tells us how much a person feels independent in actions and decisions, and if she perceives herself as being competent and in contact with other people. The scale has 9 items scored on a 5-point Likert scale, from 1 ("not at all true") to 5 ("very true"). A bigger score indicates higher satisfaction of basic psychological needs. The Cronbach $\alpha$ index of internal consistency was .79 .

Authenticity was examined with the Authenticity Scale (Wood, Linley, Maltby, Baliousis, \& Joseph, 2008), a 12 item self-report instrument, scored on a 7 point Likert scale, from 1 ("does not describe me at all") to 7 ("describes me very well"). An example of an item is "I make my own choices in life". A higher score indicates better authenticity. Cronbach $\alpha$ for this scale was .82 .

Neuroticism was measured with the NeuroticismAnxiety subscale of Zuckerman - Kuhlman Personality Questionnaire (Zuckerman, Kuhlman, Joireman, Teta, \& et al, 1993). This subscale has 19 self-report true or false items regarding worry, fearfulness, indecision and selfconfidence. The Cronbach $\alpha$ internal consistency coefficient was .83 .

Dispositional optimism was evaluated with Life Orientation Test (Scheier, Carver, \& Bridges, 1994), a selfreport questionnaire, with 14 items, measured on a 5-point Likert scale, from 0 ("strongly disagree") to 4 ("strongly agree"). An example of an item is this: "Overall, I expect more good things to happen to me than bad.". The Cronbach $\alpha$ internal consistency index was .75.

\section{Results}

The means and standard deviations for the investigated variables in this study are presented in Table 1 while Table 2 depicts the zero order correlations between the variables. To test the mediating model we used the multiple regression analysis in SPSS.

H1: Optimism as a mediator in the relationship between self-authenticiy and the need for autonomy

Optimism mediates the relationship between selfauthenticity and the satisfaction of the need for autonomy. The results are summarised in Table 3. Self-authenticity is a significant predictor for the satisfaction of the need for autonomy and it explains $32 \%$ of its variance $(\beta=.56$, $\left.R^{2}=.32, \quad p<0.001\right)$. Self-authenticity is a significant predictor for optimism and it explains $16 \%$ of its variance $\left(\beta=.40, R^{2}=.16, p<0.001\right)$. Self-authenticity and optimism predict the satisfaction of the need for autonomy and explain $39 \%$ of its variance $\left(R^{2}=39, p<0.001\right)$. Therefore, optimism partially mediates the connection between selfauthenticity and need for autonomy.

Self-authentic people tend to be more optimistic and thus they have a greater chance to do what they really want and to feel autonomous in their lives.

H2: Optimism as a mediator in the relationship between self-authenticity and the satisfaction of the need for competence.

Optimism mediates the relationship between selfauthenticity and the satisfaction of the need for competence. The results are summarised in Table 4. Selfauthenticity is a significant predictor for the satisfaction of the need for competence and it explains $14 \%$ of its variance $\left(\beta=.38, R^{2}=.14, p<0.001\right)$. Self-authenticity is a significant predictor for optimism and it explains $16 \%$ of its variance $\left(\beta=.40, R^{2}=.16, p<0.001\right)$. Self-authenticity and optimism predict the satisfaction of the need for competence and explain $36 \%$ of its variance $\left(R^{2}=.36\right.$, $p<0.001)$. Therefore, optimism partially mediates selfauthenticity and the need for competence.

Self-authentic people tend to be more optimistic and thus have a greater chance to satisfy their need for competence. We can assume that their optimistic attitude helps in finding new ways to solve problems at work or to find new opportunities in their career, and this may contribute to their feeling of competence. These assumptions must be tested in further research studies.

Table 1. Descriptive statistics

\begin{tabular}{|c|c|c|}
\hline Variable & Mean (M) & Standard deviation (SD) \\
\hline BPN satisfaction & 35.13 & 5.18 \\
\hline Self-authenticity & 63.65 & 12.11 \\
\hline Dispositional optimism & 44.52 & 7,01 \\
\hline Neuroticism & 6.85 & 4.54 \\
\hline The need for autonomy & 12,37 & 2,28 \\
\hline The need for competence & 11,65 & 2,28 \\
\hline The need for relatedness & 11,11 & 2,06 \\
\hline
\end{tabular}


Table 2. Correlations between study variables

\begin{tabular}{|c|c|c|c|c|c|c|c|}
\hline Variables & 1 & 2 & 3 & 4 & 5 & 6 & 7 \\
\hline 1. Self-authenticity & & & & & & & \\
\hline 2. Optimism & $.40 * *$ & & & & & & \\
\hline 3. Neuroticism & $-.53 * *$ & $-.55^{* *}$ & & & & & \\
\hline $\begin{array}{l}\text { 4. Basic psychological } \\
\text { need satisfaction }\end{array}$ & $.50 * *$ & $.67 * *$ & $-.52 * *$ & - & & & \\
\hline 5. Need for autonomy & $.56^{* *}$ & $.48 * *$ & $-.49^{* *}$ & $.78^{* *}$ & & & \\
\hline 6. Need for competence & $.38 * *$ & $.58 * *$ & $-.40 * *$ & $.81 * *$ & $.46 * *$ & & \\
\hline 7. Need for relatedness & $.21 * *$ & $.50 * *$ & $-.32 * *$ & $.74 * *$ & $.34 * *$ & $.43 * *$ & \\
\hline
\end{tabular}

Table 3. Optimism as a mediator between self-authenticity and the satisfaction of the need for autonomy

\begin{tabular}{|c|c|c|c|c|c|}
\hline Predictor variable & B & $\boldsymbol{\beta}$ & $\mathbf{t}$ & Sig. (p) & $\begin{array}{l}\text { R square } \\
\text { change }\end{array}$ \\
\hline Model 1 & & & & & \\
\hline $\begin{array}{l}\text { Self-authenticity } \\
\mathrm{R} \text { square }=.32 \\
\text { Criterion variable: } \\
\text { Satisfaction of the need } \\
\text { for autonomy }\end{array}$ & .10 & .56 & 10,83 & .000 & $.32 * *$ \\
\hline Model 2 & & & & & \\
\hline $\begin{array}{l}\text { Self-authenticity } \\
\mathrm{R} \text { square }=.16 \\
\text { Criterion variable: } \\
\text { Optimism }\end{array}$ & .23 & .40 & 6,91 & .000 & $.16^{* *}$ \\
\hline Model 3 & & & & & \\
\hline $\begin{array}{l}\text { Self-authenticity } \\
\text { Optimism } \\
\mathrm{R} \text { square }=.39 \\
\text { Criterion variable } \\
\text { Satisfaction of the need } \\
\text { for autonomy }\end{array}$ & $\begin{array}{l}.08 \\
.10\end{array}$ & $\begin{array}{l}.44 \\
.30\end{array}$ & $\begin{array}{l}8,23 \\
5,70\end{array}$ & $\begin{array}{l}.000 \\
.000\end{array}$ & $.07 * *$ \\
\hline
\end{tabular}

Table 4. Optimism as a mediator between self-authenticity and the satisfaction of the need for competence

\begin{tabular}{lcccc}
\hline Predictor variable & B & $\boldsymbol{\beta}$ & $\mathbf{t}$ & $\begin{array}{c}\text { Sig. (p) } \\
\text { square } \\
\text { Model 1 }\end{array}$ \\
$\begin{array}{l}\text { Self-authenticity } \\
\text { R square }=.14\end{array}$ & .07 & .38 & 6,48 & .000 \\
$\begin{array}{l}\text { Criterion variable: } \\
\text { Satisfaction of the need }\end{array}$ & & & \\
for competence & & & $.14 * *$ \\
\end{tabular}

Model 2

Self-authenticity

.23

.40

6,91

.000

$.16 * *$

R square $=.16$

Criterion variable:

Optimism

Model 3

\begin{tabular}{|c|c|c|c|c|c|}
\hline Self-authenticity & .03 & .17 & 3,14 & .002 & \\
\hline Optimism & .16 & .51 & 9,34 & .000 & $.22 * *$ \\
\hline \multicolumn{6}{|l|}{$\mathrm{R}$ square $=.36$} \\
\hline \multicolumn{6}{|l|}{ Criterion variable } \\
\hline \multicolumn{6}{|c|}{ Satisfaction of the need } \\
\hline for competence & & & & & \\
\hline
\end{tabular}


Table 5. Predictors of basic psychological need satisfaction

\begin{tabular}{lllll}
\hline Predictor Variable & $\boldsymbol{\beta}$ & $\mathbf{t}$ & Sig. (p) & $\begin{array}{l}\text { R square } \\
\text { change }\end{array}$ \\
Self-authenticity & .23 & 4,50 & .000 & $.25^{* *}$ \\
Optimism & .51 & 9,61 & .000 & $.61^{* *}$ \\
Neuroticism & -.11 & $-1,92$ & .05 & $.007^{*}$ \\
R square $=.52$ & & & & \\
\hline \multicolumn{2}{c}{ Notes. $* \mathrm{p}<.05, * * \mathrm{p}<.01}$. & & &
\end{tabular}

H3: Optimism mediates the relationship between selfauthenticity and the satisfaction of the need for relatedness

Optimism did not mediate the relationship between self-authenticity and the satisfaction of the need for relatedness. This result could be explained by the fact that optimism implies an orientation towards the future and towards activity (for example goal pursuing). So, optimism implies some expectancies for desirable outcomes, those outcomes correspond to different life goals and engage a focus on activity, on doing (like achieving a feeling of autonomy in one's life or a feeling of competence in the work field) rather than on being (the need for relatedness can be studied better from "a being perspective" - to have authentic relationships with the others: this is perceived by the human mind as happening in the present. An optimistic attitude implies a perspective on the future and achievements in different life areas).

The predictive role of personality factors for basic psychological needs satisfaction

H4. We postulated that self-authenticity, optimism, and neuroticism predict altogether one's basic psychological need satisfaction. More precisely, self-authentic people who are also optimistic and have a low level of neuroticism will have a stronger feeling that their basic psychological needs are accurately satisfied.

The results displayed in Table 5 show that selfauthenticity, optimism, and neuroticism predict altogether the basic psychological needs satisfaction, explaining $52 \%$ of the variance in the criterion variable $\left(R^{2}=.50, p<0.05\right)$. Neuroticism is a negative predictor of BPN satisfaction $\left(\beta=-.11, R^{2}\right.$ change $\left.=.007, p<0.05\right)$.

\section{Discussion}

Using the self-determination theory (Deci \& Ryan, 2000) as a theoretical framework, this paper aimed at investigating the mediating role of dispositional optimism and on the relationship between self-authenticity and basic psychological needs satisfaction and the predictive role of three personality factors (self-authenticity, neuroticism, and optimism) on basic psychological needs satisfaction. Previous inquiries brought evidence that these personality traits are predictors of BPN satisfaction (Desrumaux et al., 2015; Ionescu, 2017).

The present study revealed dispositional optimism is a stronger predictor for BPN satisfaction $\left(\beta=.51, R^{2}\right.$ change $\left.=.61^{* *}, \quad p<0.001\right)$ than neuroticism $\left(\beta=-.11, R^{2}\right.$ change $=.007 *, p<0.05)$. The finding is evidence that positive personality traits may be stronger predictors for BPN satisfaction than negative traits, but further investigations are needed to establish that. Self-authentic individuals, with a high level of optimism and a low level of neuroticism, tend to feel more autonomous, connected with those around them and competent in their work field. Self- authenticity is a fundamental factor (see Deci \& Ryan, 2000) for long term happiness and fulfillment, so we can presume that self-authentic people engage in those activities that have the potential to bring them what they really want in life, being well aware of those things (see Elliot \&Sheldon, 1997). With optimism and a low level of negative emotionality (specific for the neurotic person), an individual can have the strenght to follow his goals and identify oportunities to satisfy his real psychological needs.

Self-authentic individuals tend to be more optimistic and have a bigger BPN satisfaction. An optimistic person can act accordingly to her own desires and goals and can engage herself in actions that satisfy the three basic psychological needs. Also, it is possible that optimism's bracing impact upon affectivity to direct the person towards action. Positive expectations for the future are associated with better coping mechanisms and the "I can manage" feeling (Michael F. Scheier \& Carver, 1993) that opens the door to self-concordant goal achievement and BPN satisfaction. In contrast, it is unlikely for an individual with high neuroticism to act in a self-concordant manner and satisfy his needs for competence, autonomy, and relatedness. Other papers already brought evidence that such a person depletes her resources on managing negative emotions or affect-related goals (Baumeister et al., 2007; Reisz et al., 2013). Our results are consistent with the literature and bring additional explicative value to prior explorations.

This paper highlighted that self-authentic individuals tend to be more optimistic and thus they have a greater chance for satisfying their psychological needs for autonomy and relatedness (feeling autonomous and achieving a feeling of competence in their work). Optimism is an important resource that can contribute to a positive attitude towards life and its diverse aspects. It is possible that optimistic people identify more life opportunities for satisfying their psychological needs.

Self-authenticity reflects a good capacity of knowing one's own needs and acting accordingly to accomplish them. A deficit in this area means that the person is not aware of what the self-concordant needs are and what is to be done to satisfy them. If neuroticism is added, this process becomes even harder. Heller, Komar, \& Lee (2007) examined within-subject fluctuations in neuroticism and extraversion and their role in approach-avoidance goals. As expected, the results showed that neuroticism predisposes people to avoidance goals. This leads to a decline in goal pursuit progress and, of course, low basic needs satisfaction.

Also, this study brought to attention that self-authentic individuals who are also optimistic and less neurotic, have a greater chance of satisfying their basic psychological needs. A person who is authentic with his own self knows what she wants, what she feels and will merely engage in activities that better define her. This kind of attitude and behavior can lead to positive emotions as an outcome and a 
low frequency of negative emotions, in contrast with the neurotic person who feels more often negative emotions. Negative emotionality can be a serious bias for achieving one's life goals and satisfying his basic psychological needs.

\section{Limits and Future research directions}

The present investigation has several limitations worth mentioning in order to accurately interpret the reported results. First of all, the cross-sectional nature of the study does not allow causal inferences, which decreases the explicative power of the findings. Second of all, the analysis is based on a convenience sample from the Romanian general population, which limits the generalization of outcomes. Also, the relationships investigated in this study could be influenced by the contribution of covariates (e.g. socio-economic status or social support)

From a clinical perspective, it would be useful to test out hypotheses on special populations, where goal pursuit is clinically affected (e.g., depression, anxiety disorders). A recent review highlighted the importance of using SDT in the clinical field and the shortage of studies in this direction (Riggenbach et al., 2019).

\section{References}

Baumeister, R. F., Vohs, K. D., \& Tice, D. M. (2007). The strength model of self-control. Current Directions in Psychological Science, 16(6), 351-355. https://doi.org/10.1111/j.1467-8721.2007.00534.x

Chang, E. C., D'Zurilla, T. J., \& Maydeu-Olivares, A. (1994). Assessing the dimensionality of optimism and pessimism using a multi-measure approach. Cognitive Therapy and Research, 18(2),

$143-160$. https://doi.org/10.1007/BF02357221

Conversano, C., Rotondo, A., Lensi, E., Della Vista, O., Arpone, F., \& Reda, M. A. (2010). Optimism and its impact on mental and physical well-being. Clinical Practice \& Epidemiology in Mental Health, 6(1), 25-29. https://doi.org/10.2174/1745017901006010025

Cordeiro, P., Paixão, P., Lens, W., Lacante, M., \& Luyckx, K. (2016). The Portuguese validation of the Basic Psychological Need Satisfaction and Frustration Scale: Concurrent and longitudinal relations to well-being and ill-being. Psychologica Belgica, 56(3), 193-209. https://doi.org/10.5334/pb.252

Costa, P. T., \& McCrae, R. R. (1992). The Five-Factor Model of Personality and its relevance to personality disorders. Journal of Personality Disorders, 6(4), 343-359. https://doi.org/10.1521/pedi.1992.6.4.343

Deci, E. L., \& Ryan, R. M. (2000). The "what" and "why" of goal pursuits: Human needs and the self-determination of behavior. Psychological Inquiry, 11(4), 227-268. https://doi.org/10.1207/S15327965PLI1104_01

Desrumaux, P., Lapointe, D., Ntsame Sima, M., Boudrias, J.S., Savoie, A., \& Brunet, L. (2015). The impact of job demands, climate, and optimism on well-being and distress at work: What are the mediating effects of basic psychological need satisfaction? Revue Européenne de Psychologie Appliquée/European Review of Applied Psychology, 65(4), 179-188. https://doi.org/10.1016/j.erap.2015.06.003

Elliot, A. J., Sheldon, K. M., \& Church, M. A. (1997). Avoidance personal goals and subjective well-being. Personality and Social Psychology Bulletin, 23(9), 915927. https://doi.org/10.1177/0146167297239001

Gillard, A., \& Roark, M. F. (2013). Support for basic psychological needs in the context of HIV disclosure for older youth. Children and Youth Services Review, 35(1), 102-111. https://doi.org/10.1016/j.childyouth.2012.10.021

Halama, P., \& Dedova, M. (2007). Meaning in life and hope as predictors of positive mental health: Do they explain residual variance not predicted by personality traits? Studia Psychologica, 49(3), 191-200.

Heller, D., Komar, J., \& Lee, W. B. (2007). The dynamics of personality states, goals, and well-being. Personality and Social Psychology Bulletin, 33(6), 898-910. https://doi.org/10.1177/0146167207301010

Ionescu, D. (2017). The process of life goals' pursuit and the satisfaction of basic psychological needs: The predictive role of personality factors. Romanian Journal of Applied Psychology, 19(1), 23-29. https://doi.org/10.24913/rjap.19.1.04

Judge, T. A., Bono, J. E., Erez, A., \& Locke, E. A. (2005). Core self-evaluations and job and life satisfaction: The role of self-concordance and goal attainment. Journal of Applied Psychology, 90(2), 257-268. https://doi.org/10.1037/0021-9010.90.2.257

Knee, C. R., \& Zuckerman, M. (1998). A nondefensive personality: Autonomy and control as moderators of defensive coping and self-handicapping. Journal of Research in Personality, 32(2), 115-130. https://doi.org/10.1006/jrpe.1997.2207

Kovess-Masféty, V. (2003). Les indicateurs de santé mentale [Mental health indicators]. In Projets du programme européen propositions d'indicateurs. (No. 42; pp. 53-57). Actualité et Dossier en Santé Publique.

Nishimura, T., \& Suzuki, T. (2016). Basic psychological need satisfaction and frustration in Japan: controlling for the big five personality traits: Need satisfaction and frustration in Japan. Japanese Psychological Research, 58(4), 320-331. https://doi.org/10.1111/jpr.12131

Ormel, J., Rosmalen, J., \& Farmer, A. (2004). Neuroticism: a non-informative marker of vulnerability to psychopathology. Social Psychiatry and Psychiatric Epidemiology, 39(11), 906-912. https://doi.org/10.1007/s00127-004-0873-y

Peterson, C., \& Seligman, M. E. (1987). Explanatory style and illness. Journal of Personality, 55(2), 237-265.

Quested, E., \& Duda, J. L. (2010). Exploring the socialenvironmental determinants of well- and ill-being in dancers: A test of basic needs theory. Journal of Sport \& Exercise Psychology, 32(1), 39-60.

Reisz, Z., Boudreaux, M. J., \& Ozer, D. J. (2013). Personality traits and the prediction of personal goals. Personality and Individual Differences, 55(6), 699-704. https://doi.org/10.1016/j.paid.2013.05.023

Riggenbach, A., Goubert, L., Van Petegem, S., \& Amouroux, R. (2019). Topical review: Basic psychological needs in adolescents with chronic pain-a self-determination perspective. Pain Research and Management, 2019, 1-12. https://doi.org/10.1155/2019/8629581

Saricaoğlu, H., \& Arslan, C. (2013). An investigation into psychological well-being levels of higher education students with respect to personality traits and selfcompassion. Educational Sciences: Theory \& Practice. https://doi.org/10.12738/estp.2013.4.1740

Scheier, M. F., Carver, C. S., \& Bridges, M. W. (1994). Distinguishing optimism from neuroticism (and trait anxiety, self-mastery, and self-esteem): a reevaluation of the Life Orientation Test. Journal of Personality and Social Psychology, 67(6), 1063-1078.

Scheier, Michael F., \& Carver, C. S. (1985). Optimism, coping, and health: Assessment and implications of generalized outcome expectancies. Health Psychology, 4(3), 219-247. https://doi.org/10.1037/0278-6133.4.3.219

Scheier, Michael F., \& Carver, C. S. (1993). On the power of positive thinking: The benefits of being optimistic. 
Current Directions in Psychological Science, 2(1), 26-30. https://doi.org/10.1111/1467-8721.ep10770572

Sedikides, C., Slabu, L., Lenton, A., \& Thomaes, S. (2017). State authenticity. Current Directions in Psychological Science, 26(6), https://doi.org/10.1177/0963721417713296

Wasylkiw, L., Fabrigar, L. R., Rainboth, S., Reid, A., \& Steen, C. (2010). Neuroticism and the architecture of the self: exploring neuroticism as a moderator of the impact of ideal self-discrepancies on emotion. Journal of Personality, $78(2)$ 471-492. https://doi.org/10.1111/j.1467-6494.2010.00623.x

Wood, A. M., Linley, P. A., Maltby, J., Baliousis, M., \& Joseph, S. (2008). The authentic personality: A theoretical and empirical conceptualization and the development of the Authenticity Scale. Journal of Counseling Psychology,
55(3), 385-399. https://doi.org/10.1037/00220167.55.3.385

Wrosch, C., \& Scheier, M. F. (2003). Personality and quality of life: The importance of optimism and goal adjustment. Quality of Life Research: An International Journal of Quality of Life Aspects of Treatment, Care \& Rehabilitation, 12(1suppl), 59-72. https://doi.org/10.1023/A:1023529606137

Zuckerman, M., Kuhlman, D. M., Joireman, J., Teta, P., \& et al. (1993). A comparison of three structural models for personality: The Big Three, the Big Five, and the Alternative Five. Journal of Personality and Social Psychology, 65(4), 757-768. https://doi.org/10.1037/00223514.65.4.757 